France Boisvert est née le 10 juin 1959 à Sherbrooke. En 1985 elle obtient une maîtrise en création littéraire de l'Université de Sherbrooke, non avoir cré un précédent en déposant un mémoire en bande dessinée. Elle a travaillé comme institutrice d'équitation, secrétaire, journaliste pigiste, animatrice à la radio et rédactrice en chef de la revue Nex: Nouvelle expression. Elle enseigne actuellement le français dans un collège privé, le Séminaire Salésien.

\title{
Oeuvres:
}

Participante au collectif Oulipo Québec in La nouvelle barre du jour (Montréal), janvier 1984.

Li Tsing-tao ou le grand avoir, conte en vers libres (Montreal: Editions de l'Hexagone, coll. Fictions, 1989); Le Grand avoir, in Moebius [Montréal] 41 (octobre 1989); Les Samourailles, roman (Montréal: Editions de l'Hexagone, coll. Fictions, 1987); La Trace de Médée, in Arcade [Montréal] (février 87); Les Amarantes, in Arcade (février 85); L'Enigmatique éclipse de si bémol in La nouvelle barre du jour [Montreal] (juin 84); Chercher la femme qui cherche in La nouvelle barre du jour (avril 1984).

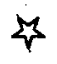

\section{Massawipi (extrait)}

Je repose auprès du Massawipi

un lac

une pièce d'eau

un pays de flots

ses rives sont faites

pour abreuver les cerfs vidés

voilà des germinations odorantes

et du cerfeuil clair

la nuit chante dans les herbes

bientôt la source des forêts

l'eau de feu la sève l'érable.

Je viens m'y réfléchir

les couleurs brûlent

partout l'automme roux 
mais rien ne fume ni ne crie

tout s'alanguit dans la torpeur

les bêtes marmonnent dans leur tanière

c'est la nuit tout dort.

Dans un shack abandonné

une shed de tôle et de bois

cabane à sucre des Canadas

j'orchestre de minutieux rituels

sous la bruine acide des pluies sacrées.

J'hypnotise jonquilles et narcisses

petites momies de soleils chinés

et plus tard à l'aube

dans la couche d'air jauni

l'ozone trouée de biphéniles polychlorés

par brassée dans une jonque sans quille

les glisserai vers la rive du lac

leurs tiges servant de mat

les larges pétales de voiles.

Déjà elles sèchent à ravir

ces fleurs qui n'en sont plus

deviennement fragile papier pâle

et gerbe mortuaire

sur l'onde fougerole.

Je termine l'ceuvre du deuil

sa lecture acte posthume

et ici ici encore

le vent frise le lac

le pays ne me revient pas

voici l'arrière saison l'été indien

derniers soleils de l'équinoxe échue

chimie terrestre des astronomies décalées. 
Je suis venue seule

rencontrer l'âme du lac

j'ai posé en offrande

une boîte sur le sol

au bout du sentier qui mène

sur la grève avant le quai

près des roseaux

sur la pierre longue

et sous de si lents cieux

sans attendre cent ans tendres

j'ai défait les noeuds de couleuvres

orange bleu rose rouge jaune et mauve

les couleurs grouillaient dans mes mains vives

et l'ai ouverte ourlée de rires

tirant au loin les serpentines.

Une lune s'est échappée

glissa grise sur le lac d' ardoise

vacillant entre le reflet et sa lumière

l'ombre vigoureuse des flots d'acier

se cambra lissant les pics d'emaux d'eau

puis grimpa se hissa et monta encore

enivrée par l'infini vertige

pour se diluer

ne laissant plus que la clarté.

Immolee dans les cieux

la lune sur le lac

échevelée en rayons d'argent

s'est liee aux astres

parcours des étoiles oxydées

coeurs de soleil purs.

Tour d'ivoire plâtrée de givre

pays de verre et de cristaux

l'hiver est inévitable fatidique 
chez moi l'eau circule dans les caloriferes

et ma maison est un bateau

flots de silence où craquent les murs

si dense où claquent les plafonds

bientôt la neige ne pas penser

devant l'écran balayé

les signaux ne mènent nulle part.

Faïence de prières psalmodie de paille

chiffres de lumière et de l'adresse aux anges

tous les chemins mènent partout

hier le mercure s'est liquéfié

les thermomètres ont perdu la mesure

j'en ai ri

croyant que I'hiver retardait

rhapsodie de farenheigt.

Depuis le jour s'est levé

avec son visage de bilingue

sa vitrine mal léchée

découvrant menue grumeleuse

la poutine des jours

Je me souviens pourtant

la lune sur le lac

toujours ronde et pleine

réverbère soliloque

amie fidele ange sublime

voix céleste d'un chant qui oscille

entre l'apparat et sa disparition.

Le Québec un lac

à marée basse

avant l'hiver. 
Les bras tendus

à mon tour

je l'appelle

elle a un nom

Massawipi.

Sans rire au-dessus de l'eau

miroir à portée de main

j'effleure l'onde grisée bleue

l'eau est froide morte noyée

il me suffit d'avancer dans l'eau

tant que j'aurai pied

ne mourrai pas.

Je plonge aujourd'hui

sans scaphandre risque

l'engloutissement fatidique

suffocation infernale

le manque d'air

pour retrouver l'épave imbibée

débris chiffonnés brouillon en loques

se déploie ma jeunesse chavirée

révulsée de haine et de douleur

je souffle mon air par la bouche

comment t'apaiseras-tu

petite soeur.

Ame de peine gribouillee

noir fantôme étalé devant moi

jeune et triste tuée

respire à nouveau

accouchée à peau blème

le corps déformé par l'eau

le lac luit dans l'automne roux

je suis dans l'eau noir jusqu'au cou. 
J'ai transgressé la loi

pour t'enfanter au noir

sans permis ni permissions

hors des institutions

par tous les diables de la terre

va en paix.

Sors du lac

habite désormais mon corps entier

le seul pays qui existat

telle l'étrangère qui observe du dehors

les carcasses d' un vieux pays encore fumant

la puanteur des dogmes des cures des cours

incarnés dans la parole d'hommes de robe

éternels fils de personne

à la solde d'une justice périmée

enracinés dans le rêve d'une théocratie

la vérité unique ultime totalitaire.

Je te baptise

Massawipi

au nom du Ciel de la Terre

et de la vie entière. 